\title{
New generation of Sour Service Drill Pipe allows addressing highly sour field challenges
}

\author{
A. Thomazic ${ }^{1}$, R. Rodrigues ${ }^{2}$, F. Thebault ${ }^{1}$, S. Mauries ${ }^{2}$, V. Flores ${ }^{3}$ and E. Lambet ${ }^{1}$ \\ ${ }^{1}$ Vallourec Research Aulnoye, Aulnoye-Aymeries, France \\ 2 Vallourec Group, Aulnoye-Aymeries, France \\ ${ }^{3}$ Vallourec Group, Houston, USA
}

\begin{abstract}
Drill pipes are commonly produced by assembling pipe and tool joints through friction welding. The weld, as a result of this process, presents some challenges for preserving corrosion resistance due to some metallurgical factors such as heterogeneous microstructure, different chemical compositions between the tool joint and the pipe body and heterogeneous mechanical properties close to the welded line. Hence a new drill pipe configuration have been developed including modified chemical composition and modified manufacturing process. These modifications allow for the improvement of mechanical properties performance and corrosion resistance in the welded zone.
\end{abstract}

\section{INTRODUCTION}

With the increasing demand of gas worldwide, some highly sour oil and gas reservoirs have been explored in Russia, Middle East, China and North America. The development of such fields, which contain a high percentage of sour gas, represents significant technical challenges regarding drill pipe integrity and operations safety. Sour Service drill pipe has long been used with tool joints and tubes fulfilling separate criteria for Sour Service as defined by several industry standards. The friction weld was not considered for Sulfide Stress Cracking (SSC) resistance. They present some challenges for preserving SSC resistance due to some metallurgical factors such as heterogeneous microstructure, different chemical compositions between the tool joint and the pipe body and high hardness values close to the welded line. Hence a new drill pipe configuration, with yield strength range of 105-120 ksi (724-827 MPa), has been developed including modified chemical composition and modified manufacturing process.

\section{STANDARD SOUR SERVICE DRILL PIPE}

The standard sour service $105 \mathrm{ksi}$ (724 MPa) grade drill pipes are produced with different chemical composition between mother pipe and tool joints. Both parts are fully compliant with IRP 1.8 requirements. The weld is performed by friction welding followed by local postwelding heat treatment by induction.

Even with some dedicated process, the SSC resistance of welds evaluated by NACE TM0177-2005 Method A in NACE Solution A is limited to $260 \mathrm{MPa}$ (36\% of specified minimum yield strength). Some properties, as hardness, yield strength and microstructure seem to be a clue to explain these poor performances.

\section{Hardness}

It is well known that the hardness gives quantitative information on the SSC susceptibility of a material

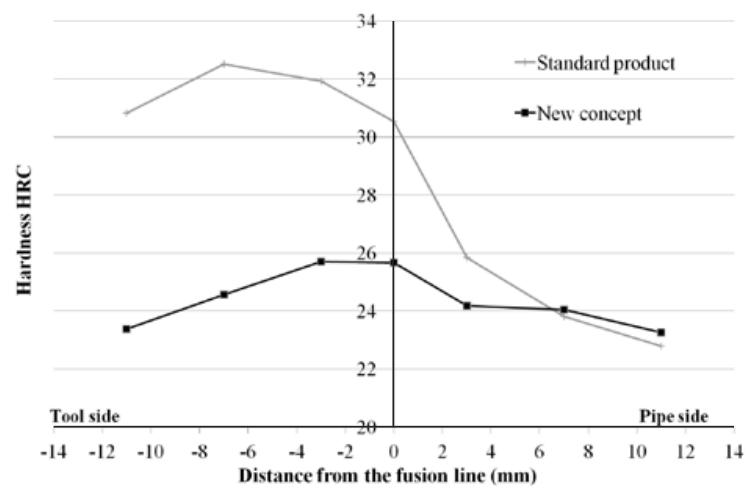

Figure 1. Hardness (HRC) profile of weld area of standard and optimized sour service drill pipes.

[1-3]. SSC failures concern only high strength steels and the hardest, the most sensitive to SSC the steel is. For instance NACE MR0175 points out 22 HRC as the critical value of hardness for low alloy steel. Therefore, the hardness is one of the most used parameter to foresee the SSC resistance of a weld even if the hardness alone is not sufficient to foresee the risk precisely.

Hardness measurements were performed on blanks before NACE samples machining. All results are available in figure 1 . For standard products, there is a significantly gap about $6 \mathrm{HRC}$ between the pipe body and tool joint.

Another important point is the hardness in the fusion line that is higher than $30 \mathrm{HRC}$. Moreover, on microhardness mapping of the weld area, weld line is spotted with hard points between 310-340 HV0.1 whereas matrix hardness is about 270-280 HV0.1 (Fig. 2).

All these points have to be avoided in order to improve the SSC resistance.

\section{Tensile properties}

Due to the lack of homogeneity of the weld area between mother pipe and tool joint, heat affected zone and weld line, results of tensile tests can not be totally representative 


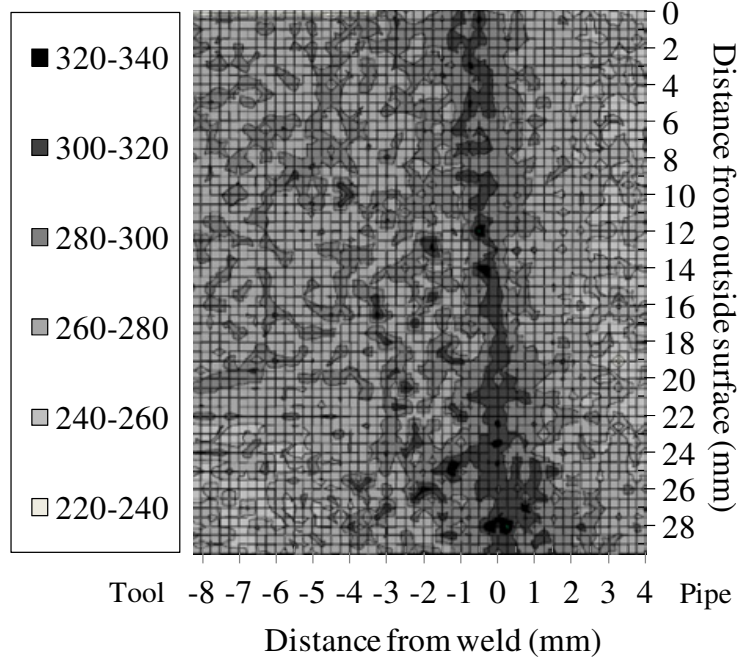

Figure 2. Microhardness (HV0.1) mapping of weld area of standard sour service drill pipes.

of the weld. In most cases, the weld shows harder areas than a complete drill pipes. That's why we decided to implement a new tensile specimen with reduced gauge length $(20 \mathrm{~mm})$ and diameter $(4 \mathrm{~mm})$, more related to NACE specimen dimensions and focused only on weld area. Whereas standard tensile specimens achieve yield strength (YS) about $740 \mathrm{MPa}$ (fracture at $30 \mathrm{~mm}$ from weld), the sub-size samples are more representative of the weld with YS above $900 \mathrm{MPa}$ (fracture close to weld line). This result is compliant with the hard zone detected by microhardness mapping, and illustrates the SSC susceptibility of the weld.

\section{Microstructure}

Apart from weld area, microstructure consists of tempered martensite. Due to the different chemical composition and welding process, Heat Affected Zone (HAZ) and weld line have heterogeneous microstructure, even after appropriate heat-treatment.

\section{Results on sour service properties}

The reason for the low performance in the weld can be easily explained by the high hardness and high yield strength close to the fusion line combined with heterogeneous microstructure due to the different chemical composition.

\section{OPTIMIZED SOUR SERVICE DRILL PIPE}

To increase the corrosion resistance in the weld zone, some improvements have been done on the chemistry, friction weld process and post-welding heat treatment. All these parameters are key factors for SSC resistance improvements. Regarding the chemical composition, the

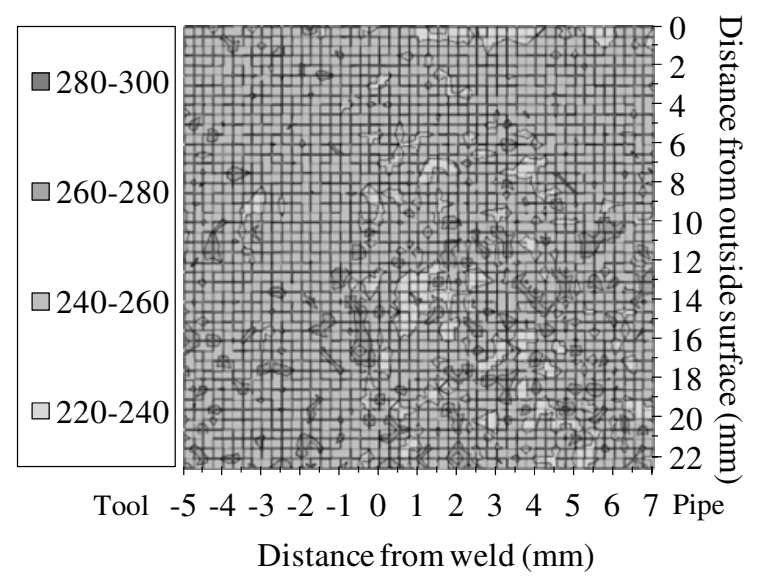

Figure 3. Microhardness (HV0.1) mapping of weld area of optimized sour service drill pipes.

goal is to get the tool joint chemistry as close as possible to the pipe body. This should decrease the heterogeneity (hardness, microstructure) of the HAZ due to a more stable post-welding heat treatment with closer chemical compositions. In addition, galvanic coupling or interdiffusion of alloying element at the fusion weld during the welding process should be avoided [4]. In terms of welding process and post-welding heat treatment, the goal is to reduce as much as possible the hardness of the fusion line, as explained above.

Several trials were performed with the new concept and all mechanical properties have been compared with the standard Sour Service grade.

\section{Hardness}

Hardness gap between the pipe body and the tool joint is in a reduced range of $2 \mathrm{HRC}$, including the fusion line (Fig. 1). This is mainly due to the change in chemistry. Furthermore, the weld line is no more noticeable on microhardness mapping (Fig. 3). That was improved by optimization of process parameters, including postwelding heat treatment.

\section{Tensile properties}

Yield strength measured by standard and sub-size samples are really close, about $715 \mathrm{MPa}$ and $730 \mathrm{MPa}$ respectively. This confirms the absence of hard zone in weld line.

\section{Microstructure}

Microstructure is homogeneous and consists of tempered martensite, even in HAZ. The weld line is no more obvious, and an appropriate etching is needed to reveal it more clearly. Grain size is homogeneous from tool part to pipe body and around 8-9. 


\section{Sour service properties}

Better performance was observed for the new concept. In fact, first trials with an applied stress of $434 \mathrm{MPa}(60 \%$ of specified minimum yield strength) were all successful. More tests will be performed to estimate the threshold stress for this new configuration.

\section{CONCLUSION}

With the modification on the chemical composition and better control of the welding process and post-welding heat treatment, the welded zone is more homogeneous in terms of mechanical properties and microstructure. Besides, no more hard points are detected on the weld line. Both points have a direct positive influence on the NACE test resistance, and the threshold stress was improved by at least $65 \%$.

\section{References}

[1] M.B. Kermani, C. Boucher, J.L. Crolet, J. Enerhaug, P. Fassina, R. Howard, J.P. Jansen, C. Linne, R. Popperling, Limits of linepipe weld hardness for domains of sour service in oil and gas production, NACE conference, paper $\mathrm{n}^{\circ} \mathbf{1 5 7}$ (2000).

[2] Written by the Task Group T-1F-23 on sulfide stress cracking resistance of pipeline welds, SSC resistance of pipeline welds, MP, January (1993) 58.

[3] V.M. Tkach, L.V. Kapinos, R.K. Melekhov, Influence of heat treatment on the sulfide cracking susceptibility of welded joints of pipe steel, Materials Science, 29 (1993) 685.

[4] Y. Tsukano, H. Asahi, T. Terasawa, M. Ueno, Development of sour service drillstring with 110-ksi yield strength, IADC/SPE Drilling Conference, paper n 22004 (1991). 